\title{
Antagonistic effect of protein extracts from Streptococcus sanguinis on pathogenic bacteria and fungi of the oral cavity
}

\author{
SHENGLI MA ${ }^{1}$, HUI LI ${ }^{1}$, CHUANG YAN $^{1}$, DAN WANG ${ }^{1}$, HAIQING $^{1}{ }^{1}$, XUE XIA $^{1}$, XUE DONG $^{1}$, \\ YINGNAN ZHAO $^{1}$, TINGTING SUN $^{2}$, PENGFEI HU ${ }^{2}$ and WEIJUN GUAN ${ }^{2}$ \\ ${ }^{1}$ Department of Stomatology, Hospital of Heilongjiang Province, Harbin, Heilongjiang 150036; \\ ${ }^{2}$ Institute of Animal Sciences, Chinese Academy of Agricultural Sciences, Beijing 100193, P.R. China
}

Received September 5, 2013; Accepted February 24, 2014

DOI: $10.3892 / \mathrm{etm} .2014 .1618$

\begin{abstract}
An antibacterial substance from Streptococcus sanguinis (S. sanguinis) is known to have an inhibitory effect on putative periodontal pathogens, but its inhibitory effect on pathogens of oral candidiasis is unknown. In this study, intracellular and exocrine proteins were extracted from $S$. sanguinis. The antagonistic effect of the protein extracts on Prevotella intermedia (P. intermedia) and Porphyromonas gingivalis ( $P$. gingivalis) was detected by a well-plate technique, and the effects of the protein extracts on biofilms formed by these bacteria were evaluated by confocal laser scanning microscopy. The antagonistic effect of the protein extracts on pathogenic fungi was investigated using Candida albicans (C.albicans) and Candida tropicalis (C. tropicalis). The growth curves of $C$. albicans and $C$. tropicalis were determined from ultraviolet absorption measurements, their morphological changes following treatment were observed by optical microscopy and scanning electron microscopy, and the effects of the protein extracts on the thickness of their biofilms and the distribution of dead/live bacteria within the biofilms were detected by confocal laser scanning microscopy. The results showed significant inhibitory effects of the intracellular proteins extracted from $S$. sanguinis on pathogenic bacteria ( $P$. intermedia and $P$. gingivalis), fungi (C. albicans and $C$.tropicalis) and the biofilms formed by them. Furthermore, the growth curves and morphology of C. albicans and $C$.tropicalis were altered following treatment with the intracellular proteins, resulting in disc-like depressions in the surfaces of the fungal spores and mycelia. By contrast, the exocrine proteins demonstrated no significant inhibitory effect
\end{abstract}

Correspondence to: Dr Shengli Ma, Department of Stomatology, Hospital of Heilongjiang Province, 82 Zhongshan Road, Harbin, Heilongjiang 150036, P.R. China

E-mail:mslsci@163.com

Key words: Streptococcus sanguinis, intracellular proteins, exocrine proteins, antagonistic effect, bacteria, fungi on the pathogenic bacteria, fungi and the biofilms formed by them. Thus, it may be concluded that intracellular proteins of S. sanguinis have antibacterial activity and exert an antagonistic effect on certain pathogenic bacteria and fungi of the oral cavity.

\section{Introduction}

Streptococcus sanguinis ( $S$. sanguinis) is the dominant bacteria in a healthy oral cavity and it is generally accepted that an antibacterial substance generated by $S$. sanguinis has an inhibitory effect on putative periodontal pathogens. The main mechanism of this effect is the generation of hydrogen peroxide and bacteriocin, and the latter mainly functions under anaerobic conditions $(1,2)$. It has been reported that bacteriocin accumulates in bacterial cells when $S$. sanguinis is cultured under anaerobic conditions, and is not released into the extracellular environment $(3,4)$. However, antibacterial substances were detected in the culture medium of $S$. sanguinis in one particular study (5). The inhibitory effect of the antibacterial substance from S. sanguinis on the pathogens of oral candidiasis is unknown.

A previous study showed that there are considerable quantities of Prevotella intermedia (P. intermedia) and Porphyromonas gingivalis ( $P$. gingivalis) in the subgingival plaque of adult patients with moderate or serious periodontitis (6). These two bacteria adhere and colonize under the gingiva. Disorganization of the periodontal supporting tissue and immune response of the body are initiated by these virulence factors, which play an important role in the development of periodontal diseases. Numerous studies have focused on investigating the biological functions of $P$. intermedia and $P$. gingivalis and elucidating their mechanisms of pathogenesis (7-10).

Candida is a common pathogenic yeast that induces deep fungal infections (11). The infection rate of Candida has increased greatly with the wide use of antibiotics, hormones and immune agents (12). A mixed infection of multiple Candida species is frequently detected in the oral cavity of patients with AIDS. The most common type of mixed infection is reported to be Candida albicans (C. albicans) complicated 
by Candida tropicalis (C.tropicalis), and C.albicans complicated by Candida glabrata or Candida krusei has also been observed (13), with $C$. albicans and $C$.tropicalis having the highest pathogenicity.

In the present study, intracellular and exocrine proteins were extracted from $S$. sanguinis and, using $P$. intermedia, $P$. gingivalis, $C$. albicans and $C$. tropicalis as indicators, the biological effects of the protein extracts on pathogenic bacteria and fungi were detected and analyzed.

\section{Materials and methods}

Extraction and purification of the intracellular and exocrine proteins from S. sanguinis. The standard strain ATCC 10556 of S. sanguinis was purchased from the State Key Laboratory of Oral Diseases, West China College of Stomatology, Sichuan University (Chengdu, China). Following identification and pure culture, the bacteria were inoculated on Brain Heart Infusion (BHI) culture medium and anaerobically cultured for $48 \mathrm{~h}$.

Intracellular proteins. The medium of S. sanguinis was ultracentrifuged at a low temperature following the anaerobic culture. The bacterial precipitate was collected, washed and resuspended in phosphate-buffered saline (PBS). The target proteins were released from the cells by sonication and the supernatant was collected by centrifugation $\left(12,000 \times \mathrm{g}, 4^{\circ} \mathrm{C}\right.$, $30 \mathrm{~min}$ ). Solid ammonium sulfate was slowly added to the supernatant to yield $60 \%$ saturation, salted out for $6 \mathrm{~h}$ at $4^{\circ} \mathrm{C}$ and centrifuged to isolate the supernatant. Subsequently, the collections were subjected to a second round of salting out with $70 \%$ saturation and, following centrifugation, the precipitate was dissolved in PBS. The desalting purification was conducted by chromatography on Sephadex G-25 (Pharmacia, Picastaway, NJ, USA). The collected materials were dialyzed, condensed, lyophilized and cryopreserved.

Exocrine proteins. The medium of S. sanguinis was ultracentrifuged $\left(10,000 \mathrm{x} \mathrm{g}, 4^{\circ} \mathrm{C}, 10 \mathrm{~min}\right)$ following the anaerobic culture. The supernatant was collected and an equal volume of cold anhydrous ethanol was added. The mixture was allowed to stand for $6 \mathrm{~h}$ at $4^{\circ} \mathrm{C}$ and then centrifuged. The precipitate was resuspended in PBS and cryopreserved.

$P$. intermedia and $P$. gingivalis. The standard strains ATCC 25611 and ATCC 33277 of P. intermedia and P. gingivalis, respectively, were purchased from Beijing Stomatological Hospital, Capital Medical University (Beijing, China). The purified and identified $P$. intermedia and $P$. gingivalis were diluted to $1 \times 10^{8} \mathrm{cfu} / \mathrm{ml}$ and a mixture of $P$. intermedia and $P$. gingivalis (ratio 1:1) was also prepared.

Minimal inhibitory concentrations (MICs) of the protein extracts against $P$. intermedia and $P$. gingivalis. The MICs were detected by a well-plate technique. P. intermedia suspension $(20 \mu \mathrm{l})$ was placed on a blood agar plate, spread evenly and two holes were punched with an aseptic puncher. The diameter of the holes was $5 \mathrm{~mm}$. The agar in the hole was removed and sealed with melted BHI solid medium on the bottom (half the depth). Subsequently, $20 \mu l$ intracellular or exocrine $S$. sanguinis proteins were added to the holes and anaerobically cultured for
$48 \mathrm{~h}$ at $37^{\circ} \mathrm{C}$. The $P$. gingivalis and $P$. intermedia $+P$. gingivalis suspensions were treated by the same method. The MICs of the intracellular $S$. sanguinis proteins were determined by a double dilution method. The proteins were diluted to $0.5,0.25$, $0.125,0.0625,0.0313$ and $0.0156 \mathrm{~g} / \mathrm{l}$ with PBS. Subsequently, $20 \mu \mathrm{l}$ dilutions to the equal volume of bacterial suspensions were obtained. Following complete mixing, $20 \mu \mathrm{l}$ suspensions were spread evenly on the blood agar plates and anaerobically cultured for $48 \mathrm{~h}$ at $37^{\circ} \mathrm{C}$. The MIC of the intracellular proteins of $S$. sanguinis against the $P$. intermedia and $P$. gingivalis co-culture was observed and calculated.

Effects of the S. sanguinis proteins on biofilms formed by $P$. intermedia and $P$. gingivalis. A sterile cover glass with $500 \mu \mathrm{l} P$. intermedia and $P$. gingivalis mixture was placed into a six-well plate, allowed to stand for $10 \mathrm{~min}$ and then $2 \mathrm{ml} \mathrm{BHI}$ culture medium was slowly added and the mixture was anaerobically cultured for $48 \mathrm{~h}$ at $37^{\circ} \mathrm{C}$ to ensure that the planktonic $P$. intermedia and $P$. gingivalis were attached. Intracellular proteins $(1 \mathrm{~g} / \mathrm{l})$ were slowly added to one well of the plate, exocrine proteins were slowly added to another well, and an equal volume of deionized water was added to the last well. The liquid from each well was carefully removed after $1 \mathrm{~h}$ treatment and the wells were washed with $1 \mathrm{ml}$ PBS. Acridine orange (AO) and ethidium bromide (EB) were diluted to $100 \mathrm{mg} / \mathrm{l}$ with $\mathrm{PBS}$, the dilutions were mixed and re-diluted 20-fold, added to the wells, and observed under a confocal laser scanning microscope (Leica CTR6500; Leica, Wetzlar, Germany). When the live bacterial DNA combined with AO, bright green fluorescence was observed, and when the dead bacterial DNA combined with EB, red fluorescence was observed. Yellow or orange fluorescence indicated the overlap of live and dead bacteria. Biofilm viability $(\mathrm{BV} ; \%)=$ green fluorescence/(green fluorescence + red fluorescence) x 100 .

C. albicans and $C$. tropicalis. The standard strains ATCC 10231 and ATCC 13803 of C. albicans and C.tropicalis, respectively, were purchased from the National Center for Medical Culture Collections (Beijing, China). The purified and identified $C$. albicans and $C$. tropicalis were diluted to $1 \times 10^{6} \mathrm{cfu} / \mathrm{ml}$ with RPMI-1640 culture medium, and a mixture of $C$. albicans and $C$.tropicalis (ratio 1:1) was also prepared.

MICs of the protein extracts against $C$. albicans and C. tropicalis. The MICs of the $S$. sanguinis protein extracts against C. albicans, $C$. tropicalis and their co-cultures were detected using a well-plate technique. The intracellular and exocrine proteins of $S$. sanguinis were diluted to $0.25,0.5$ and $1 \mathrm{~g} / \mathrm{l}$ with PBS. The tests were performed on three groups. In the first group, $C$. albicans suspension $(10 \mu \mathrm{l})$ was inoculated into a culture tube with $1 \mathrm{ml}$ RPMI-1640 and $300 \mu \mathrm{l}$ intracellular proteins. In the second group, $C$. albicans suspension $(10 \mu \mathrm{l})$ was inoculated into a culture tube with $1 \mathrm{ml}$ RPMI-1640 and $300 \mu 1$ exocrine proteins. Group three was used as a control without any protein extracts. The test groups were cultured at $37^{\circ} \mathrm{C}$ with agitation for $12 \mathrm{~h}$; then they were sampled and the bacterial culture was counted. The MICs of the S. sanguinis protein extracts against the C.tropicalis culture and C.albicans and $C$.tropicalis co-culture were observed and calculated using the same method. 
Table I. Shorthand and substances of the groups in each experiment.

\begin{tabular}{|c|c|c|c|c|}
\hline Group & $\begin{array}{l}\text { Intracellular proteins } \\
\qquad 1 \mathrm{~g} / 1\end{array}$ & $\begin{array}{l}\text { C.albicans } \\
\text { suspension }\end{array}$ & $\begin{array}{l}\text { C.tropicalis } \\
\text { suspension }\end{array}$ & $\begin{array}{l}\text { RPMI-1640 } \\
\text { medium }\end{array}$ \\
\hline \multicolumn{5}{|l|}{ Treatment } \\
\hline Intracellular proteins $C$. albicans & $300 \mu 1$ & $10 \mu 1$ & - & $10 \mathrm{ml}$ \\
\hline Intracellular proteins $C$. tropicalis & $300 \mu 1$ & - & $10 \mu 1$ & $10 \mathrm{ml}$ \\
\hline Intracellular proteins co-cultures & $300 \mu 1$ & $5 \mu 1$ & $5 \mu 1$ & $10 \mathrm{ml}$ \\
\hline \multicolumn{5}{|l|}{ Control } \\
\hline C.albicans & - & $10 \mu 1$ & - & $10 \mathrm{ml}$ \\
\hline C.tropicalis & - & - & $10 \mu 1$ & $10 \mathrm{ml}$ \\
\hline C. albicans and C.tropicalis & - & $5 \mu 1$ & $5 \mu 1$ & $10 \mathrm{ml}$ \\
\hline
\end{tabular}

C. albicans, Candida albicans; C. tropicalis, Candida tropicalis.

Table II. Inhibitory effect of the bacterial intracellular and exocrine proteins of S. sanguinis on P. intermedia and $P$. gingivalis.

\begin{tabular}{lccc}
\hline Bacteria & Intracellular proteins & MIC $(\mathrm{g} / \mathrm{l})$ & Exocrine proteins \\
\hline P. intermedia & + & 0.1250 & - \\
$P$. gingivalis & + & 0.0625 & - \\
$P$. intermedia + P. gingivalis & + & 0.1250 & - \\
\hline
\end{tabular}

'+' represents inhibition of bacterial growth, '-' represents no inhibition of bacterial growth. P. intermedia, Prevotella intermedia; P. gingivalis, Porphyromonas gingivalis; S. sanguinis, Streptococcus sanguinis; MIC, minimal inhibitory concentration of the intracellular proteins.

Effects of the S. sanguinis proteins on biofilms formed by C. albicans and C. tropicalis. The biofilm models of $C$. albicans and $C$.tropicalis were established by the same method as that described for $P$. intermedia and $P$. gingivalis. The effects of the intracellular and exocrine proteins on the biofilm models were tested, $500 \mu \mathrm{l}$ proteins ( $1 \mathrm{~g} / \mathrm{l})$ were added, $500 \mu 15.25 \%$ chlorhexidine was used as positive control, two techniques were used: Continuous tomography to determine the thickness of the biofilms, and dynamic observation of adherent viable/dead bacteria in the different periods of biofilm formation.

Effects of the intracellular proteins on the growth of C. albicans and $C$.tropicalis. The tests were performed on two groups (Table I). Each group was cultured at $37^{\circ} \mathrm{C}$ and agitated, and the optical density (OD) value at $600 \mathrm{~nm}$ was tested every $2 \mathrm{~h}$. Growth curves (y-axis, OD value and $\mathrm{x}$-axis, incubation time) were plotted to assess the proliferation ability of each group.

Effects of the intracellular proteins on the morphology of C. albicans and C.tropicalis. The tests were performed on two groups (Table I). Each group was cultured at $37^{\circ} \mathrm{C}$ and agitated for $12 \mathrm{~h}$ and histological examination was conducted to observe the morphology by optical microscopy (OM; SH11/YF-9, Shenzhen Xingyu Xin Electronics Co., Ltd., Guangdong, China) and scanning electron microscopy (SEM; Magellan XHR, FEI, USA).

Statistics and analysis. X-test, one-way analysis of variance and logistic analysis were conducted using SPSS 16.0 to make statistical analysis. $\mathrm{P}<0.05$ was considered to indicate a statically significant result.

\section{Results}

Effects of the protein extracts on P. intermedia and P. gingivalis Inhibitory effect. A marked inhibitory effect of the intracellular proteins on the growth of $P$. intermedia and $P$. gingivalis was observed, while the exocrine proteins appeared to be inactive. The MIC of the intracellular proteins against the co-culture of $P$. intermedia and $P$. gingivalis was $0.125 \mathrm{~g} / 1$ (Table II).

Results tested by confocal laser scanning microscopy. A significant reduction in the percentage of viable cells in the $P$. intermedia and $P$. gingivalis co-cultural biofilm following treatment with the intracellular proteins was observed compared with that of the control biofilm $(\mathrm{P}<0.05)$, while no significant change following treatment with the exocrine proteins was identified compared with that of the control group (Table III and Fig. 1).

Effects of the protein extracts on C. albicans and C. tropicalis Inhibitory effect. A significant inhibitory effect of the intracellular proteins on the growth of $C$. albicans and $C$.tropicalis was observed compared with that of the control group, while the exocrine proteins did not have a significant effect. When the concentration of the intracellular proteins was $1 \mathrm{~g} / \mathrm{l}$, the number of fungal colonies was significantly different between the $C$. albicans, $C$.tropicalis and their co-culture groups and the corresponding control group (Table IV). 
Table III. Effects of the intracellular and exocrine proteins of S. sanguinis on the viability of the biofilms formed by the P. intermedia and $P$. gingivalis co-culture (\%, mean \pm standard deviation).

\begin{tabular}{lccc}
\hline Measured Item & Intracellular proteins & Exocrine proteins & Deionized water \\
\hline Biofilm Viability & $28.33 \pm 3.87^{\mathrm{a}}$ & $54.41 \pm 4.12$ & $56.44 \pm 4.79$ \\
\hline
\end{tabular}

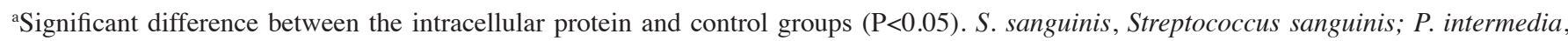
Prevotella intermedia; $P$. gingivalis, Porphyromonas gingivalis.

Table IV. Inhibitory effect of the intracellular and exocrine proteins of S. sanguinis on C. albicans and C. tropicalis $\left(10^{6} \mathrm{cfu} / \mathrm{ml}\right.$, mean \pm standard deviation).

\begin{tabular}{|c|c|c|c|c|c|c|c|}
\hline \multirow[b]{2}{*}{ Fungi } & \multicolumn{3}{|c|}{ Intracellular proteins $(\mathrm{g} / \mathrm{l})$} & \multicolumn{3}{|c|}{ Exocrine proteins (g/l) } & \multirow[b]{2}{*}{ Control group } \\
\hline & 0.25 & 0.5 & 1 & 0.25 & 0.5 & 1 & \\
\hline C. albicans & $1.95 \pm 0.26$ & $1.86 \pm 0.31$ & $0.72 \pm 0.13^{\mathrm{a}}$ & $1.98 \pm 0.19$ & $1.96 \pm 0.09$ & $1.98 \pm 0.32$ & $2.12 \pm 0.14$ \\
\hline C. tropicalis & $1.87 \pm 0.29$ & $1.70 \pm 0.36$ & $0.72 \pm 0.18^{a}$ & $2.13 \pm 0.21$ & $1.97 \pm 1.03$ & $1.83 \pm 0.28$ & $2.07 \pm 0.15$ \\
\hline $\begin{array}{l}\text { C. albicans }+ \\
\text { C. tropicalis }\end{array}$ & $1.85 \pm 0.18$ & $1.70 \pm 0.34$ & $0.69 \pm 0.13^{\mathrm{a}}$ & $2.05 \pm 0.14$ & $1.89 \pm 0.22$ & $1.85 \pm 0.15$ & $2.11 \pm 0.17$ \\
\hline
\end{tabular}

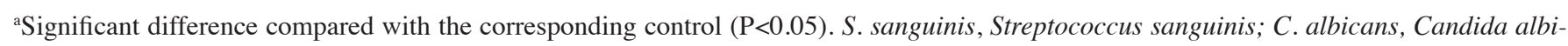
cans; C. tropicalis, Candida tropicalis.

Table V. C. albicans biofilm thickness at different time points ( $\mu \mathrm{m}$, mean \pm standard deviation).

\begin{tabular}{|c|c|c|c|c|c|}
\hline \multirow[b]{2}{*}{ Group } & \multicolumn{5}{|c|}{ Time (h) } \\
\hline & 4 & 8 & 12 & 24 & 48 \\
\hline Intracellular proteins & $33.03 \pm 1.87$ & $25.55 \pm 2.05^{\mathrm{a}}$ & $15.50 \pm 41.47^{\mathrm{a}}$ & $30.59 \pm 1.85^{\mathrm{a}}$ & $56.55 \pm 3.85$ \\
\hline Exocrine proteins & $33.28 \pm 2.15$ & $41.53 \pm 2.13$ & $42.24 \pm 2.26$ & $73.19 \pm 2.21$ & $94.03 \pm 2.66$ \\
\hline Chlorhexidine & $35.46 \pm 1.92$ & $31.55 \pm 2.59$ & $26.12 \pm 1.29$ & $24.50 \pm 1.76$ & $37.38 \pm 3.56$ \\
\hline Deionized water & $34.37 \pm 2.11$ & $40.97 \pm 1.22$ & $41.11 \pm 2.08$ & $71.20 \pm 2.52$ & $96.96 \pm 3.60$ \\
\hline
\end{tabular}

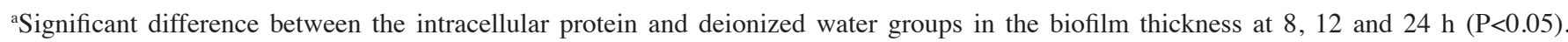
C. albicans, Candida albicans.

Table VI. C. tropicalis biofilm thickness at different time points ( $\mu \mathrm{m}$, mean \pm standard deviation).

\begin{tabular}{lccccc}
\hline & \multicolumn{5}{c}{ Time (h) } \\
\cline { 2 - 6 } Group & 4 & 8 & 12 & 24 & 48 \\
\hline Intracellular proteins & $35.33 \pm 5.74$ & $33.91 \pm 4.58^{\mathrm{a}}$ & $27.72 \pm 4.00^{\mathrm{a}}$ & $37.69 \pm 3.57^{\mathrm{a}}$ & $76.69 \pm 5.17$ \\
Exocrine proteins & $33.28 \pm 2.15$ & $47.36 \pm 2.79$ & $62.36 \pm 4.46$ & $75.18 \pm 4.60$ & $103.04 \pm 6.55$ \\
Chlorhexidine & $32.23 \pm 2.83$ & $33.13 \pm 3.63$ & $35.91 \pm 3.60$ & $42.55 \pm 5.05$ & $58.18 \pm 4.45$ \\
Deionized water & $33.91 \pm 2.06$ & $44.08 \pm 4.68$ & $58.21 \pm 3.38$ & $71.17 \pm 4.40$ & $112.26 \pm 5.27$ \\
\hline
\end{tabular}

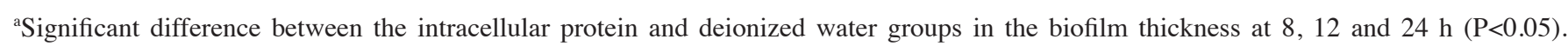
C. tropicalis, Candida tropicalis.

Results tested by confocal laser scanning microscopy. The minimum biofilm thickness of $C$. albicans and
C. tropicalis was achieved within $12 \mathrm{~h}$ in the intracellular protein groups. The thickness gradually reduced between 

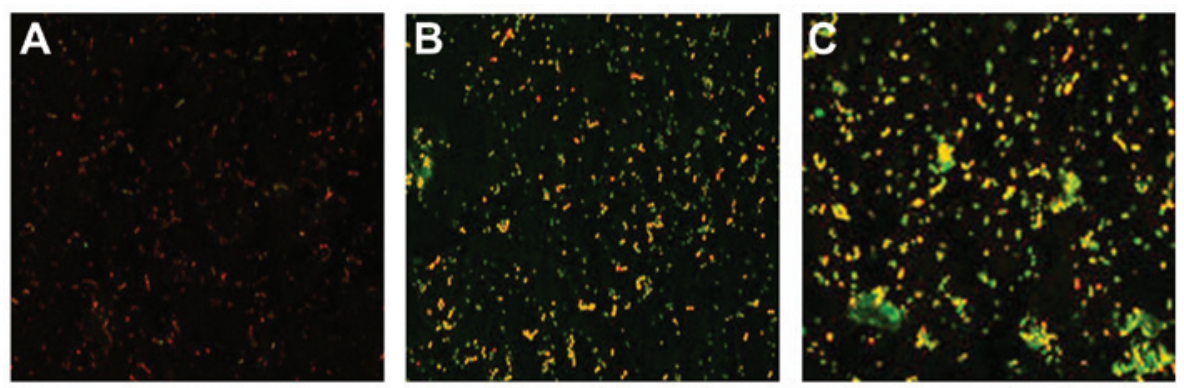

Figure 1. Distribution of the dead/viable bacteria in the biofilms formed by a $P$. intermedia and $P$. gingivalis co-culture observed by confocal laser scanning microscopy. Acridine orange (AO) and ethidium bromide (EB) staining; magnification, x200. (A) Intracellular proteins of S. sanguinis; (B) exocrine proteins of S. sanguinis; and (C) deionized water. P. intermedia, Prevotella intermedia; P. gingivalis, Porphyromonas gingivalis; S. sanguinis, Streptococcus sanguinis.
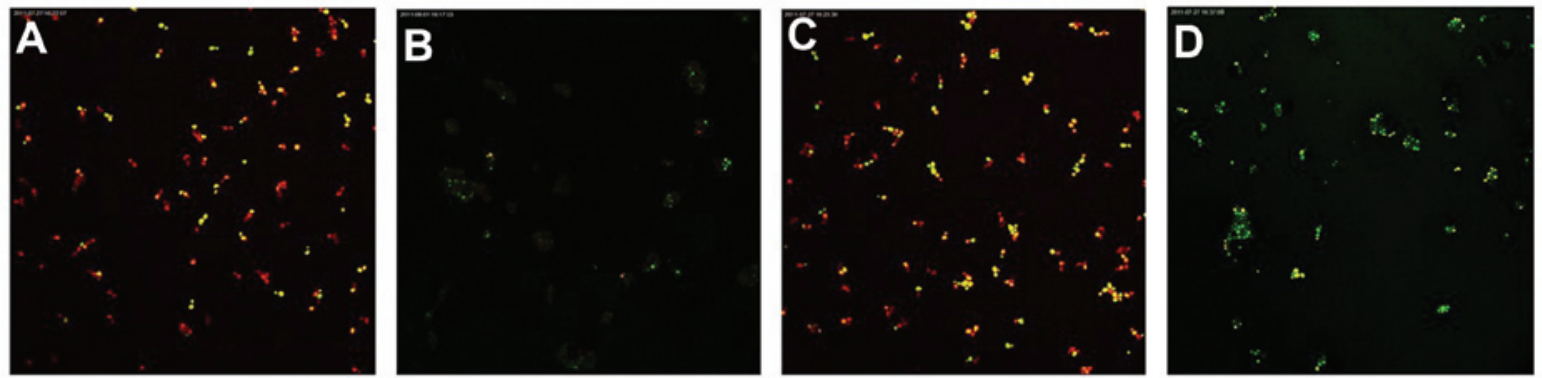

Figure 2. Distribution of dead/live fungi within the C. albicans biofilm shown by fluorescence analysis. Acridine orange (AO) and ethidium bromide (EB) staining; magnification, x200. (A) Intracellular protein, $12 \mathrm{~h}$; (B) exocrine protein, $12 \mathrm{~h}$; (C) chlorhexidine, $12 \mathrm{~h}$; and (D) deionized water, 12 h. C. albicans, Candida albicans.
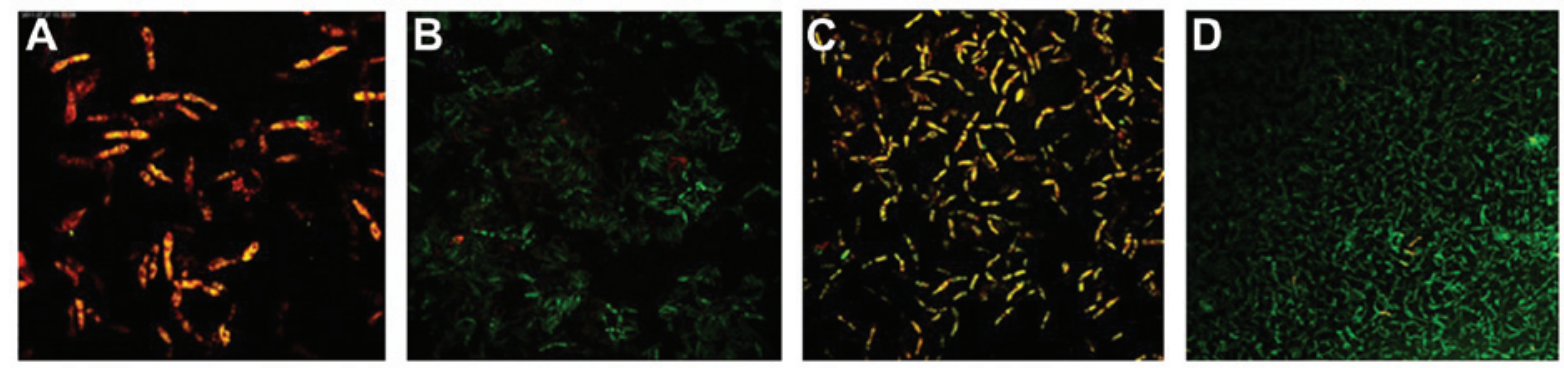

Figure 3. Distribution of dead/live fungi within the C. tropicalis biofilm shown by fluorescence analysis. Acridine orange (AO) and ethidium bromide (EB) staining; magnification, x200. (A) Intracellular protein, $12 \mathrm{~h}$; (B) exocrine protein, $12 \mathrm{~h}$; (C) chlorhexidine, $12 \mathrm{~h}$; and (D) deionized water, $12 \mathrm{~h}$. C. tropicalis, Candida tropicalis.

4 and $12 \mathrm{~h}$, and then increased between 12 and $48 \mathrm{~h}$ (Tables $\mathrm{V}$ and VI).

Following fluorescent staining, it was identified that there were a number of dead fungi present at the bottom of the biofilm formed by the C.albicans and C.tropicalis co-culture. The intermediate layer was a mixture of live and dead fungi, while there were few fungi in the surface layer. The quantity of live $C$.albicans and $C$. tropicalis following treatment with the intracellular proteins was less than that of the control group for 4-12 h, while no significant difference was observed after 24-48 h. The quantity of live C. albicans and C. tropicalis following treatment with the exocrine proteins was fundamentally the same as that of the control group (Figs. 2 and 3).

Growth curve. The OD values represent the radiation absorbed by a detected object. The turbidity of a bacterial suspension is proportional to the OD, which is precisely measured by an ultraviolet spectrophotometer; therefore, OD values represent the relative quantity of bacteria under a certain experimental condition, thus reflecting the relative amount of growth. The results showed a lag phase growth of $C$. albicans, $C$. tropicalis and their co-culture following treatment with the intracellular proteins for $14 \mathrm{~h}$ after seeding, after which the bacteria proliferated rapidly and entered a logarithmic phase, while the control groups entered this phase at $6 \mathrm{~h}$. It was indicated that the growth of C.albicans, C.tropicalis and their co-culture was inhibited by the intracellular proteins of S. sanguinis; the inhibitory effect began after $8 \mathrm{~h}$ of incubation and was no longer observed at $14 \mathrm{~h}$ (Fig. 4).

Morphological observation. Using OM, it was observed that there was a large number of spores and hyphae in the control group culture of $C$. albicans, $C$. tropicalis or their co-culture. The hyphae were different in length, and segmentally and 


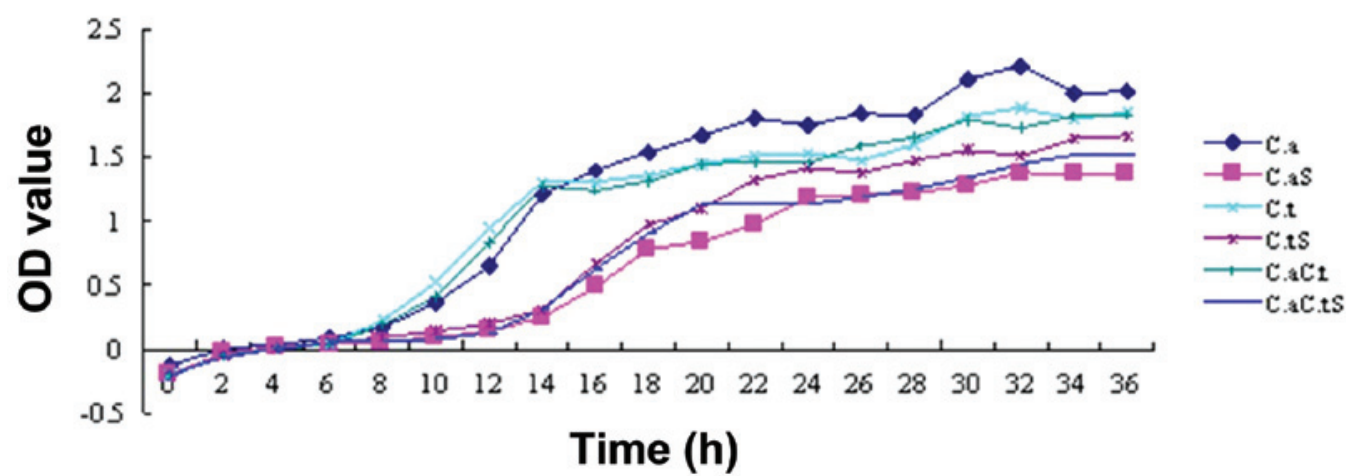

Figure 4. Effect of the intracellular proteins of Streptococcus sanguinis on the growth curves of Candida albicans (C.a), Candida tropicalis (C.t) and their co-culture (C.sC.t). C.a, C.t and C.aC.t are control cultures and C.aS, C.tS and C.aC.tS are the corresponding protein-treated cultures. OD, optical density.
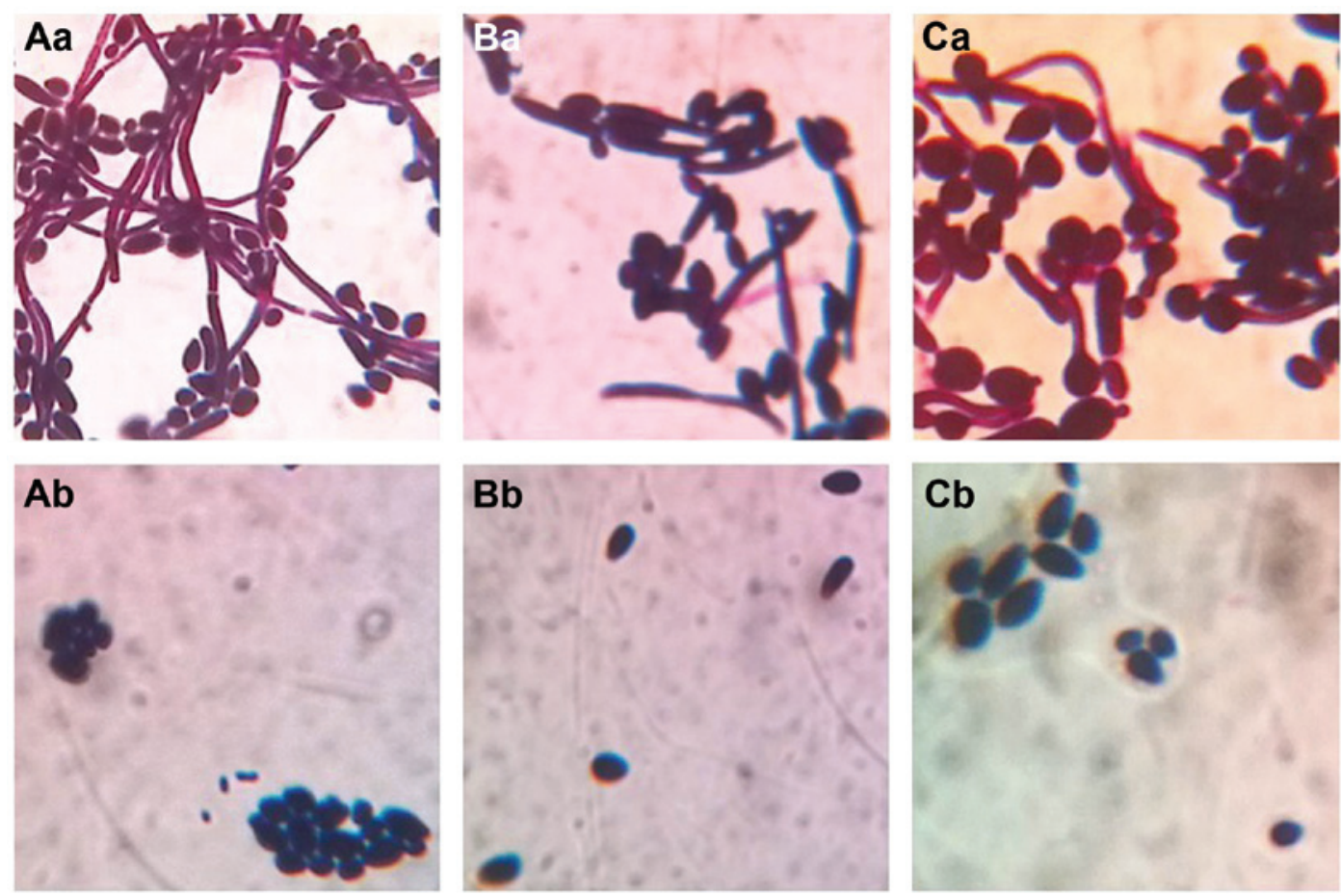

Figure 5. Morphology of C. albicans and C. tropicalis in the control and the test groups under OM observation. (Aa) C. albicans, $12 \mathrm{~h}$; (Ab) intracellular protein-treated C.albicans, $12 \mathrm{~h}$. (Ba) C. tropicalis, $12 \mathrm{~h}$; (Bb) intracellular protein-treated C. tropicalis, $12 \mathrm{~h}$. (Ca) C. albicans and C. tropicalis co-culture, 12 h; (Cb) intracellular protein-treated co-culture, 12 h. Magnification, x1,000. C. albicans, Candida albicans; C. tropicalis, Candida tropicalis; OM, optical microscopy.

irregularly distributed among round or oval spores. When treated with the intracellular proteins, the number of spores was markedly reduced, and there was no hypae growth among round or oval spores (Fig. 5).

Using SEM, it was identified that there were round or oval spores in the control group cultures of $C$. albicans and C.tropicalis; the spores were $2-5 \mu \mathrm{m}$ in diameter, had a full shape and smooth surface, and there were adhesions among a number of the spores. Round or oval spores and segmental hyphae were observed in the C.albicans and C.tropicalis co-culture control group; the spores had a full shape and smooth surface, the spore diameter was $2-5 \mu \mathrm{m}$, and the hyphae took up the entire photograph with a diameter of 1-3 $\mu \mathrm{m}$. When treated with the intracellular proteins, certain oblate or irregular spores were identified in the C.albicans and C.tropicalis monoculture groups. Disc-like depressions of different depths were present in the surfaces of the spores, and the diameter of the depressions was $0.2-0.8 \mu \mathrm{m}$. The majority of the spores had only one depression, while their surfaces were smooth and free of wrinkles. In the intracellular protein-treated C. albicans and $C$. tropicalis co-culture group, disc-like depressions were observed in the surfaces of a number of spores, and the diameter of the depressions was $0.2-0.8 \mu \mathrm{m}$. The majority of the spores had only one depression, although two depressions were occasionally observed. Depressions were also identified in the surface of the segmental hyphae. Each segment had a depression, the diameter of the hyphae was $2 \mu \mathrm{m}$ and that of the depression was $0.6 \mu \mathrm{m}$. The surfaces of the hyphae and the majority of the spores were smooth; however, wrinkles were present in the surfaces of certain spores (Fig. 6). 

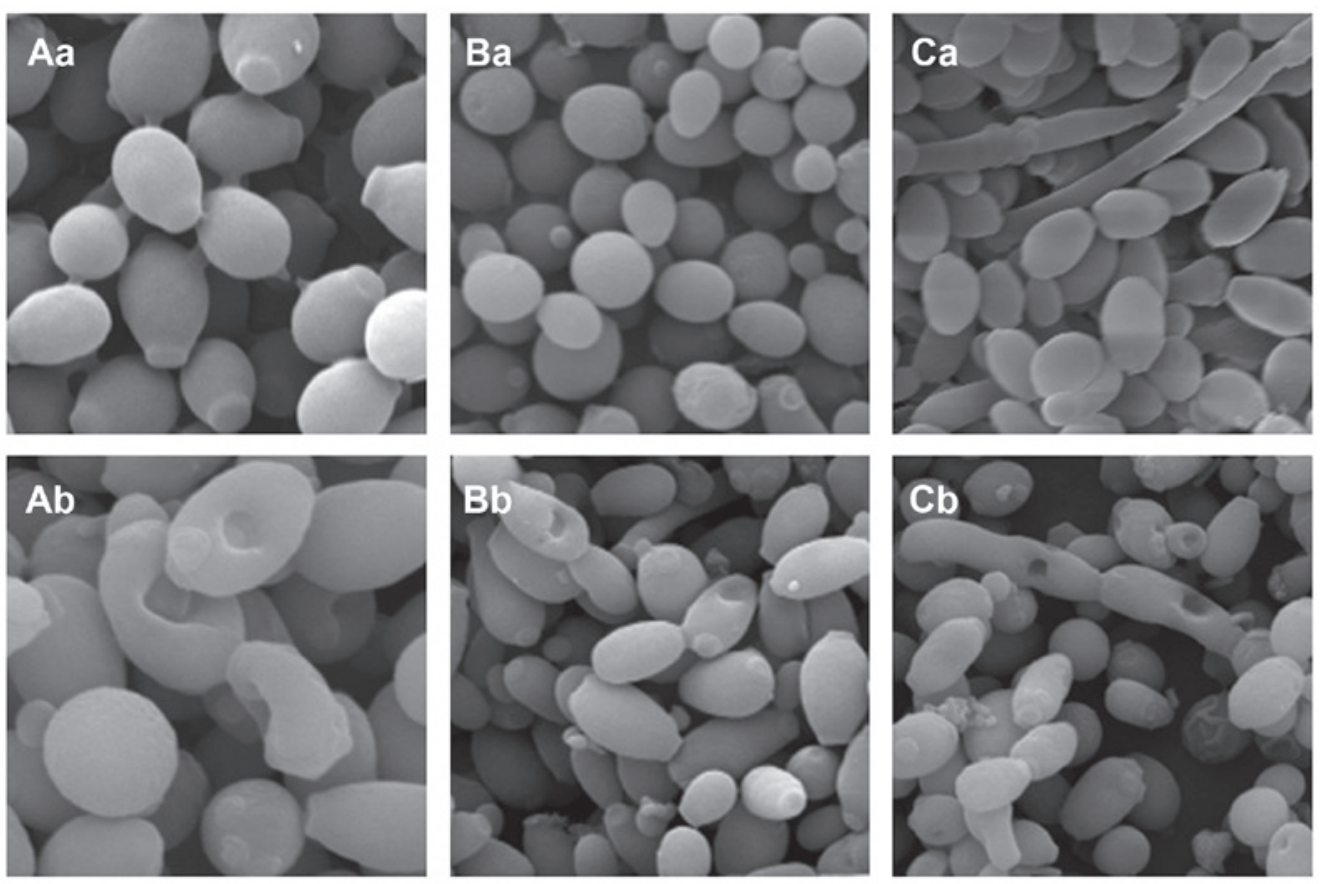

Figure 6. Morphology of C. albicans and C. tropicalis in the control and the test groups under SEM observation. (Aa) C. albicans, $12 \mathrm{~h}$; (Ab) intracellular protein-C. albicans, $12 \mathrm{~h}$ (magnification, $\mathrm{x} 4,000)$. (Ba) C. tropicalis, $12 \mathrm{~h}$; (Bb) intracellular protein-C. tropicalis, $12 \mathrm{~h}$ (magnification, $\mathrm{x} 2,000)$. (Ca) C. albicans and C. tropicalis co-cultures, $12 \mathrm{~h}$; (Cb) intracellular protein-co-cultures, $12 \mathrm{~h}$ (magnification, x2,000). C. albicans, Candida albicans; C. tropicalis, Candida tropicalis; SEM, scanning electron microscopy.

\section{Discussion}

It is controversial whether the antibacterial substance generated by $S$. sanguinis under anaerobic conditions exists in the cell or is released into the extracellular environment. In this study, intracellular and exocrine proteins were extracted from $S$. sanguinis, and their antagonistic effects on $P$. intermedia, $P$. gingivalis, $C$.albicans and $C$.tropicalis were detected. The results showed that the antibacterial substance of $S$. sanguinis was obtainable through a series of methods, namely centrifugation, ultrasonication, salting out, Sephadex G-50 filtration and dialysis. The extracts are also known as bacteriocins. The putative periodontal pathogens $P$. intermedia and $P$. gingivalis are bacteria, while $C$. albicans and $C$. tropicalis are fungi, so they are discussed separately in this study.

In the present study, a number of effects of the protein extracts on $P$. intermedia and $P$. gingivalis were observed. $P$. intermedia is a Gram-negative anaerobic bacteria that produces melanin, and is a potentially pathogenic bacteria that is frequently detected in the subgingival plaques of patients with periodontitis, pregnancy gingivitis, acute necrotizing gingivitis and human immunodeficiency virus-associated gingivitis (14). $P$. gingivalis is considered as another main periodontal pathogen, and is associated with adult periodontitis, juvenile periodontitis, periodontal abscesses, alveolar abscesses, pulp infection and refractory periodontitis (15). $P$. intermedia and $P$. gingivalis are two important putative periodontal pathogens, and their virulence factors penetrate and destroy the host tissue, allowing them to escape the host defense system. The detection rate is high in deep periodontal pockets and the attachment loss sites of periodontitis. It has been reported that the development of periodontitis is severely associated with $P$. gingivalis and moderately associated with
$P$. intermedia (16). Biofilms are the main form of survival for pathogens; they adapt themselves to the circumstances and resist attack from phagocytes, and inflammatory factors released by them cause the local inflammatory response. Complicated biofilms are the main pattern of existence of putative periodontal pathogens, and adhesive interactions between the bacteria form barriers that develop resistance to antibiotics. The results of the present study showed a marked effect of the intracellular proteins on the growth of $P$.intermedia, $P$. gingivalis and their co-cultures. Also, the biofilm viability of the $P$. intermedia and $P$. gingivalis co-culture was significantly reduced following treatment with the intracellular proteins, compared with that of the control group. It may speculated that: i) Secretory immunoglobulin A (SIgA) in the saliva plays a pivotal role in the local anti-infective immune response of the oral mucosa. SIgA may bind specifically to antigens and play an inhibitory role in sterilization through a biological effect on bacteria. As the intracellular proteins of $S$. sanguinis interacted with the biofilm formed by the $P$. intermedia and $P$. gingivalis co-culture and the viability of the biofilm was reduced, it was considered that the mechanisms of action of SIgA and S. sanguinis may be similar. ii) Certain small molecules of the intracellular proteins of $S$. sanguinis may act as ligands that specifically bind to cell-membrane or intracellular receptors of $P$. intermedia and $P$. gingivalis, and then trigger a cascade of cellular events.

In the present study, a significant inhibitory effect of the intracellular proteins on the growth of $C$. albicans, C. tropicalis and their co-culture was observed compared with that of the control groups. In clinical practice, the commonly used antifungal drugs mainly function through the inhibition of ergosterol biosynthesis, and as ergosterol is the major component of the fungal cell membrane, fungal 
growth is inhibited $(17,18)$. To investigate whether the inhibitory mechanism of the intracellular proteins of $S$. sanguinis on $C$. albicans and $C$. tropicalis was consistent with the mechanism of typical antifungal drugs, in the present study, the effects of the proteins of S. sanguinis on the morphology of $C$. albicans and $C$.tropicalis were analyzed. It was demonstrated that the number of spores and hyphae of $C$. albicans and $C$.tropicalis was markedly reduced following treatment with the intracellular proteins, and that disc-like depressions were present in the surfaces of spores and hyphae. Combined with the MIC values, the conclusion that the intracellular proteins of $S$. sanguinis not only caused the morphological changes of $C$. albicans and $C$.tropicalis, but also the inhibition of their growth was reached. There may be a number of associations between them, so it is considered that the intracellular proteins of $S$. sanguinis function through the following mechanisms: i) Numerous intracellular proteins assemble on the cell surface by electrostatic forces, which leads to a change in the distribution of certain molecules in the outer layer of the cell and eventually to a change in the morphology of the cell. ii) Intracellular proteins may specifically bind to certain substances of the cell membrane or walls of $C$. albicans and $C$.tropicalis, to cause the breakdown of the outer layer. Wiedemann et al (19) and Christ et al (20) showed that the primary force of the antibacterial effect of the bacteriocin of lactic acid bacteria is the formation of pores of diameter 2-2.5 $\mathrm{nm}$ on the surface of target cells, leading to an increase in cell membrane permeability, which allows the release of ATP, amino acids and ions from the cell. This results in bacterial metabolic disturbances and ultimately causes the death of the cell. These morphological changes are accordant with the results generated by the intracellular proteins of S. sanguinis in the present study, so it may be speculated that the antifungal effect was the result of a loss of integrity of the cell surface and changes in cell membrane permeability. Whether the intracellular proteins of S. sanguinis are able to enter cells and influence signal transduction and gene expression requires further study. iii) A certain type of enzyme may be released from $S$. sanguinis, which interacts with the cell walls through electrostatic attraction, and then the cell is depressed and lysosomal enzyme is released, which induces autocytolysis. iv) The intracellular proteins may enter the cell and inhibit the synthesis of chromosomal DNA, releasing the cytoskeleton and thereby inducing autocytolysis. v) The intracellular proteins may enter the cell and inhibit the synthesis of chromosomal DNA; this is likely to damage the cytoskeleton to a certain extent, and ultimately result in cytoskeleton collapse and the formation of disc-like depressions on the bacterial surface.

The results of the growth curve analysis in the present study indicated that the growth of $C$. albicans, $C$.tropicalis and their co-culture was inhibited by the intracellular proteins of $S$. sanguinis at a concentration of $1 \mathrm{~g} / \mathrm{l}$; the inhibition began at $8 \mathrm{~h}$ and ceased at $14 \mathrm{~h}$. The reasons for this observation may be that: i) There may be a 'half-life period' of the intracellular proteins of S. sanguinis; that is, they are degraded by fungi or fungal metabolites as the treatment time is extended. ii) The inhibition process of the intracellular proteins of S. sanguinis may be a form of active transport; the intracellular proteins are transported by an active transcellular route against the concentration gradient, and as the process requires energy expenditure, the inhibitory effect reduces gradually.

The thickness of the biofilms formed by $C$. albicans and $C$.tropicalis was reduced following treatment with the intracellular proteins within $24 \mathrm{~h}$ and minimized in $12 \mathrm{~h}$, suggesting the intracellular proteins of S. sanguinis have significant antifungal effects. It may be speculated that: i) The antifungal substance of $S$. sanguinis is located within the cell. ii) The intracellular proteins are gradually degraded by fungi or fungal metabolites, their 'half-life period' is minimized and biological activity is lost. iii) The intracellular proteins are characterized by amphoteric dissociation; when they become positively charged, the negative charges of $C$. albicans or C. tropicalis are neutralized, which triggers a cascade of cellular potential disorders and finally causes the death of the bacteria. iv) The intracellular proteins may cause changes in the osmotic balance of $C$. tropicalis in vitro and in vivo; as the proteins are gradually degraded through facilitated diffusion within $24 \mathrm{~h}$, the antifungal effect is then reduced. v) The van der Waals force between the bacteria increases along with the maturation of the biofilm, which is tightly packed, so the antifungal substance is not able to enter the biofilm and the inhibitory effect is invalidated, with little effect on the bacterial surface.

No inhibitory effect of the exocrine proteins on the growth of $P$. intermedia, $P$. gingivalis, $C$. albicans and $C$. tropicalis was observed in the present study, which is not accordant with the findings of previous studies (21). The standard strain of S. sanguinis or the culture conditions in the present study may have been different from those of the other studies, resulting in the antimicrobial substance of $S$. sanguinis not being exported out of the cell in the previous studies.

In the present study, significant inhibitory effects of the intracellular proteins of $S$. sanguinis on the growth of $P$. intermedia, $P$. gingivalis, $C$. albicans, $C$. tropicalis and their biofilms were observed, and the morphology of $C$. albicans and $C$. tropicalis was also affected. However the inhibitory mechanism of $S$. sanguinis was not identified. Whether the inhibition caused the morphological changes or the morphological changes caused the inhibition, or they were essential prerequisites of each other was not fully elucidated. Furthermore, identification of where the antimicrobial substance of S. sanguinis is located requires further study.

\section{Acknowledgements}

This study was funded by Natural Science Foundation of Heilongjiang Province (D2007-03).

\section{References}

1. Qi F and Kreth J: Characterization of anti-competitor activities produced by oral bacteria. Methods Mol Biol 666: 151-166, 2010.

2. Zhu L and Kreth J: Role of Streptococcus mutans eukaryotic-type serine/threonine protein kinase in interspecies interactions with Streptococcus sanguinis. Arch Oral Biol 55: 385-390, 2010.

3. Fujimura $S$ and Nakamura T: Sanguicin, a bacteriocin of oral Streptococcus sanguis. Antimicrob Agents Chemother 16: 262-265, 1979.

4. Hillman JD, Socransky SS and Shivers M: The relationships between streptococcal species and periodontopathic bacteria in human dental plaque. Arch Oral Biol 30: 791-795, 1985. 
5. Hammond BF, Lillard SE and Stevens RH: A bacteriocin of Actinobacillus actinomycetemcomitans. Infect Immun 55: 686-691, 1987.

6. Byrne DP, Potempa J, Olczak T and Smalley JW: Evidence of mutualism between two periodontal pathogens: co-operative haem acquisition by the HmuY haemophore of Porphyromonas gingivalis and the cysteine protease interpain A (InpA) of Prevotella intermedia. Mol Oral Microbiol 28: 219-229, 2013.

7. Sbordone L, Di Genio M and Bortolaia C: Bacterial virulence in the etiology of periodontal diseases. Minerva Stomatol 49: 485-500, 2000 (In Italian).

8. Gomes BP, Endo MS and Martinho FC: Comparison of endotoxin levels found in primary and secondary endodontic infections. J Endod 38: 1082-1086, 2012

9. López NJ: Occurrence of Actinobacillus actinomycetemcomitans, Porphyromonas gingivalis, and Prevotella intermedia in progressive adult periodontitis. J Periodontol 71: 948-954, 2000.

10. de Lillo A, Teanpaisan R, Fierro JF and Douglas CW: Binding and degradation of lactoferrin by Porphyromonas gingivalis, Prevotella intermedia and Prevotella nigrescens. FEMS Immunol Med Microbiol 14: 135-143, 1996.

11. Bruder-Nascimento A, Camargo CH, Sugizaki MF, Sadatsune T, Montelli AC, Mondelli AL and Bagagli E: Species distribution and susceptibility profile of Candida species in a Brazilian public tertiary hospital. BMC Res Notes 3: 1, 2010.

12. Azenha MR, Caliento R, Brentegani LG and de Lacerda SA: A retrospective study of oral manifestations in patients with paracoccidioidomycosis. Braz Dent J 23: 753-757, 2012.
13. Vazquez JA: Therapeutic options for the management of oropharyngeal and esophageal candidiasis in HIV/AIDS patients. HIV Clin Trials 1: 47-59, 2000.

14. Okamoto M, Maeda N, Kondo K and Leung KP: Hemolytic and hemagglutinating activities of Prevotella intermedia and Prevotella nigrescens. FEMS Microbiol Lett 178: 299-304, 1999.

15. Lakhdar L, Hmamouchi M, Rida S and Ennibi O: Antibacterial activity of essential oils against periodontal pathogens: a qualitative systematic review. Odontostomatol Trop 35: 38-46, 2012.

16. Consensus report. Periodontal diseases: pathogenesis and microbial factors. Ann Periodontol 1: 926-932, 1996.

17. Joseph-Horne T and Hollomon DW: Molecular mechanisms of azole resistance in fungi. FEMS Microbiol Lett 149: 141-149, 1997.

18. Urbina JM, Cortés JC, Palma A, López SN, Zacchino SA Enriz RD, Ribas JC and Kouznetzov VV: Inhibitors of the fungal cell wall. Synthesis of 4-aryl-4-N-arylamine-1-butenes and related compounds with inhibitory activities on beta(1-3) glucan and chitin synthases. Bioorg Med Chem 8: 691-698, 2000.

19. Wiedemann I, Benz R and Sahl HG: Lipid II-mediated pore formation by the peptide antibiotic nisin: a black lipid membrane study. J Bacteriol 186: 3259-3261, 2004.

20. Christ K, Wiedemann I, Bakowsky U, Sahl HG and Bendas G: The role of lipid II in membrane binding of and pore formation by nisin analyzed by two combined biosensor techniques. Biochim Biophys Acta 1768: 694-704, 2007.

21. Kou YR and Pan YP: Bacteriostatic activity of bacteriocin from Streptococcus sanguis. J Microbiol 2: 100-102, 2005 (In Chinese). 